\title{
A cross-sectional study of thyroid autoimmunity in women with type 2 diabetes: case for routine thyroid dysfunction screening
}

\author{
Bhujanga Shetty S. ${ }^{1 *}$, Ramachandrappa L. ${ }^{2}$ \\ DOI: https://doi.org/10.17511/ijmrr.2019.i03.15 \\ 1* Surekha Bhujanga Shetty, Assistant Professor, Karnataka Institute of Endocrinology and Research, Bangalore, Karnataka, India. \\ 2 Lalitha Ramachandrappa, Assistant Professor, Karnataka Institute of Endocrinology and Research, Bangalore, Karnataka, India.
}

Introduction: Subjects with diabetes have a higher prevalence of thyroid disorders compared to the general population. The reported prevalence of thyroid disorders is $10-24 \%$ in subjects with diabetes and $6-13 \%$ in subjects without diabetes. Auto immunity is held responsible for the increased prevalence of thyroid dysfunction in diabetes. Studies have proven the higher rates of autoimmune thyroid dysfunction in type 1 diabetes, but there is very little information regarding thyroid autoimmunity in type 2 diabetes. Objective: To estimate the prevalence of thyroid dysfunction and thyroid autoimmunity in women with type 2diabetes. Material and Methods: Samples for thyroid function test including free thyroxin (fT4), thyroid stimulating hormone (TSH) and thyroid peroxidase antibodies (anti -TPO) were obtained from 100 women with type 2 diabetes, attending the outpatient department of Karnataka Institute of Endocrinology and Research, Bangalore. Results: Thyroid dysfunction was found in $42 \%$ subjects, where $36 \%$ had subclinical hypothyroidism and $6 \%$ had overt hypothyroidism. Anti - TPO positivity was seen in $30 \%$ of the subjects. Anti-TPO positivity was found in $24.1 \%$ euthyroid subjects, $33.3 \%$ subclinical hypothyroid subjects and $66.7 \%$ overt hypothyroid subjects. Significant positive correlation was observed between anti-TPO and TSH ( $\mathrm{p}$ value $<0.001^{*}$ ). No statistically significant association was found between thyroid dysfunction and age, BMI, Hba1c, and diabetes duration. Conclusions: The prevalence of thyroid dysfunction is significantly high in women with type 2 diabetes. The most common abnormality is subclinical hypothyroidism and autoimmunity is the cause of thyroid dysfunction in large proportion of these subjects.

Keywords: Thyroid dysfunction, Type 2 diabetes, Thyroidperoxidase antibodie

\section{Corresponding Author}

Surekha Bhujanga Shetty, Assistant Professor, , Karnataka Institute of Endocrinology and Research, Bangalore, Karnataka, India.

Email: doc.surekha@gmail.com
How to Cite this Article

To Browse

Shetty SB, Ramachandrappa L, A cross-sectional study of thyroid autoimmunity in women with type 2 diabetes: case for routine thyroid dysfunction screening. Int J Med Res Rev. 2019;7(3):237-242. Available From

https://ijmrr.medresearch.in/index.php/ijmrr/article/ view/1065

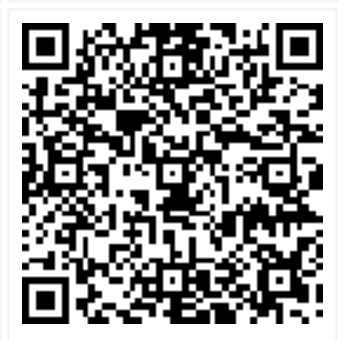

Manuscript Received 2019-05-28

Conflict of Interest No

(c)
Review Round 1 2019-06-07

Funding Nil

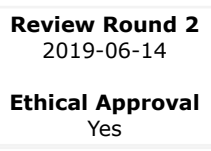

Review Round 3

Plagiarism X-checker $5 \%$
Accepted 2019-06-17

Note

(C) 2019 by Surekha Bhujanga Shetty, Lalitha Ramachandrappa and Published by Siddharth Health Research and Social Welfare Society. This is an Open Access article licensed under a Creative Commons Attribution 4.0 International License https://creativecommons.org/licenses/by/4.0/ unported [CC BY 4.0]. 


\section{Introduction}

Diabetes and thyroid dysfunction are the two most common endocrine disorders worldwide [1]. Studies have shown that diabetes and thyroid dysfunction mutually influence each other and are associated with each other frequently. Subjects with diabetes have been found to have higher prevalence of thyroid dysfunction compared to the general population. But, the prevalence of thyroid dysfunction in subjects with diabetes has been found to differ widely between different studies.

The reported prevalence of thyroid dysfunction is $10-24 \%$ in subjects with diabetes, while it is around $6-13 \%$ in subjects without diabetes [2]. Studies have shown that thyroid dysfunction is more common in women with diabetes. A recent metaanalysis revealed a mean frequency of thyroid dysfunction of $11 \%$ in diabetes. The prevalence in type 1diabetes didn't differ from those in type 2 diabetes, but the prevalence in women was consistently higher than in men [3].

The association between diabetes and thyroid dysfunction has clinically significant implications on insulin sensitivity and therapeutic approaches. Since most patients with thyroid dysfunction are asymptomatic, routine screening of subjects with diabetes for thyroid dysfunction and thyroid autoimmunity becomes important component of comprehensive evaluation and management of diabetes.

Correction of thyroid dysfunction will contribute to glycemic control in diabetes. Identification of thyroid autoimmunity will assist in assessing the future risk of developing hypothyroidism, and framing follow up strategies.

Keeping this background information in mind, the intention was to look at the prevalence of thyroid autoimmunity in the diabetic population. To establish the relationship between the diabetes and thyroid dysfunction due to auto immune pathology was the aim of the present study. Since women are at higher risk of thyroid dysfunction, women with type 2 diabetes were chosen for this study.

\section{Objectives}

To estimate the prevalence of thyroid dysfunction and thyroid autoimmunity in women with type 2 diabetes.

\section{Material and Methods}

\section{Inclusion criteria}

01 . Women with diabetes of any duration

02. Age between 18 to 65 years.

\section{Exclusion criteria}

01. Symptoms of hypothyroidism

02. Presence of goiter

03. Family history of thyroid dysfunction

04. Subjects already on thyroxine replacement

05. Subjects on drugs like amiodarone or lithium

Data collection procedures: All the subjects underwent clinical and laboratory assessment. The demographic data included information regarding age, duration of diabetes, co-morbidities like hypertension, dyslipidemia, etc and presence of complications of diabetes. BMI was calculated using the height and weight of the subjects. Samples for thyroid function test including free thyroxin (fT4), thyroid-stimulating hormone (TSH) and thyroid peroxidase antibodies (anti-TPO) were obtained. Analysis was done by chemi-lumiscence assay method. Data on HbA1c, and lipid profile also was obtained.

The reference values were $<34 \mathrm{IU} / \mathrm{ml}$ for anti-TPO; 0.93 to $1.7 \mathrm{ng} / \mathrm{dL}$ for $\mathrm{FT} 4 ; 0.27$ to $4.50 \mu \mathrm{UI} / \mathrm{ml}$ for TSH respectively. Thyroid dysfunction was classified as subclinical hypothyroidism if TSH levels were greater than $4.5 \mu \mathrm{UI} / \mathrm{ml}$ and FT4 levels ranged from $0.93 \mu \mathrm{UI}$ to $1.7 \mathrm{ng} / \mathrm{dL}$. It was further classified as mildly increased TSH levels (4.5-10.0 mIU/L) and more severely increased serum TSH levels $(>10.0$ $\mathrm{mIU} / \mathrm{L}$ ) [4].Autoimmunity was diagnosed when antiTPO levels were greater than $34 \mathrm{IU} / \mathrm{mL}$.

Ethical Approval: The ethical committee of the hospital approved the study. Informed consent for the study was obtained from all the subjects.

Statistical analysis: Data was entered into Microsoft excel data sheet and analyzed using SPSS version 22 (IBM SPSS Statistics, Somers NY, USA) software. Categorical data was represented in the form of frequencies and proportions. Chi-square test was used as test of significance for qualitative data. Continuous data was represented as mean and standard deviation. Pearson correlation or Spearman's correlation was done to find the correlation between two quantitative variables and qualitative variables respectively. 
$P$ value of $<0.05$ was considered as statistically significant after assuming all the rules of statistical tests.

\section{Results}

The study included 100 women with type 2 diabetes, selected randomly from the outpatient department of Karnataka Institute of Endocrinology and Research, Bangalore. Majority of subjects in the study were in the age group of 51 to 60 years $(44 \%)$, followed by 41 to 50 years (25\%). $38 \%$ of them had duration of diabetes between 2 to 5 years, while $33 \%$ had duration of diabetes less than 1 year. $51 \%$ of the subjects were overweight and $29 \%$ were obese. $42 \%$ of the subjects had history of hypertension and $47 \%$ had history of dyslipidemia. $5 \%$ of the subjects had diabetic nephropathy, 3\% had neuropathy and $9 \%$ had retinopathy. $77 \%$ of them had $\mathrm{HbA} 1 \mathrm{c}$ of $>6.5 \%$ (Table 1).

Table-1: Baseline characteristics of subjects in the study

\begin{tabular}{|c|c|c|c|}
\hline & & Number & $\%$ \\
\hline \multirow[t]{4}{*}{ Age } & $<40$ years & 13 & 13.0 \\
\hline & 41 to 50 years & 25 & 25.0 \\
\hline & 51 to 60 years & 44 & 44.0 \\
\hline & $>60$ years & 18 & 18.0 \\
\hline \multirow[t]{5}{*}{ Duration } & $<1$ year or New case & 33 & 33.0 \\
\hline & 2 to 5 years & 38 & 38.0 \\
\hline & 6 to 10 years & 15 & 15.0 \\
\hline & 11 to 15 years & 14 & 14.0 \\
\hline & $>15$ years & 0 & 0.0 \\
\hline \multirow[t]{2}{*}{ Hypertension } & No & 58 & 58.0 \\
\hline & Yes & 42 & 42.0 \\
\hline \multirow[t]{2}{*}{ Dyslipidemia } & No & 53 & 53.0 \\
\hline & Yes & 47 & 47.0 \\
\hline \multirow[t]{2}{*}{ CAD } & No & 95 & 95.0 \\
\hline & Yes & 5 & 5.0 \\
\hline \multirow[t]{3}{*}{ Nephropathy } & Macroalbuminuria & 2 & 2.0 \\
\hline & Microalbuminuria & 3 & 3.0 \\
\hline & Normoalbuminuria & 95 & 95.0 \\
\hline
\end{tabular}

\begin{tabular}{|l|l|l|l|}
\hline \multirow{3}{*}{ Neuropathy } & No & 97 & 97.0 \\
\cline { 2 - 4 } & Yes & 3 & 3.0 \\
\hline Retinopathy & No & 91 & 91.0 \\
\cline { 2 - 4 } & Yes & 9 & 9.0 \\
\hline BMI & Normal & 20 & 20.0 \\
\cline { 2 - 4 } & Overweight & 51 & 51.0 \\
\cline { 2 - 4 } & Obese & 29 & 29.0 \\
\hline HbA1c & $<6.5$ & 23 & 23.0 \\
\cline { 2 - 4 } & 6.6 to 7.5 & 27 & 27.0 \\
\cline { 2 - 4 } & 7.6 to 8.5 & 26 & 26.0 \\
\cline { 2 - 4 } & 8.6 to 9.5 & 24 & 24.0 \\
\hline
\end{tabular}

Table-2: Prevalence of thyroid dysfunction and anti-TPO positivity

\begin{tabular}{|c|c|c|c|}
\hline & & Number & $\%$ \\
\hline \multirow[t]{2}{*}{ Anti TPO } & $<35$ & 70 & 70.0 \\
\hline & $>35$ & 30 & 30.0 \\
\hline \multirow[t]{3}{*}{ TSH } & Normal $(<5)$ & 58 & 58.0 \\
\hline & Subclinical hypothyroidism (5 to 10 ) & 36 & 36.0 \\
\hline & Overt hypothyroidism $(>10)$ & 6 & 6.0 \\
\hline
\end{tabular}

In the study, thyroid dysfunction was found in $42 \%$ of the subjects, where $36 \%$ had subclinical hypothyroidism and $6 \%$ had overt hypothyroidism. Anti TPO positivity was seen in $30 \%$ of the subjects. Among the subjects with anti-TPOpositivity, 40\% had subclinical hypothyroidism and $13.3 \%$ had overt hypothyroidism. Among the 58 subjects with normal thyroid function, 14 (24.1\%) had anti-TPO positivity. Among 36 subjects with sub clinical hypothyroidism, 12 (33.3\%) had anti-TPO positivity and among 6 subjects with overt hypothyroidism, 4 $(66.7 \%)$ had anti-TPO positivity. No cases of hyperthyroidism were noted (Table 2 and 3 ).

Table-3: Association between Abnormal TSH and Anti-TPO.

\begin{tabular}{|l|l|l|l|l|l|}
\hline \multirow{2}{*}{\multicolumn{2}{|c|}{}} & \multicolumn{4}{|c|}{ Anti TPO } \\
\cline { 2 - 7 } \multicolumn{2}{|c|}{} & $<35$ & \multicolumn{3}{|l|}{$>35$} \\
\cline { 2 - 7 } \multicolumn{2}{|c|}{} & Number & $\%$ & Number & $\%$ \\
\hline \multirow{3}{*}{ TSH } & Normal $(<5)$ & 44 & 75.9 & 14 & 24.1 \\
\cline { 2 - 7 } & Subclinical hypothyroidism (5 to 10) & 24 & 66.7 & 12 & 33.3 \\
\cline { 2 - 7 } & Overt hypothyroidism (>10) & 2 & 33.3 & 4 & 66.7 \\
\hline
\end{tabular}

$X 2=4.98, \mathrm{df}=2, \mathrm{p}=0.0$

Table-4: Correlation between profile of subjects and abnormal TSH and Anti TPO

\begin{tabular}{|l|l|l|l|l|l|l|l|l|l|}
\hline \multicolumn{2}{|c}{} & Anti TPO & TSH & Age & Diabetes duration & BMI & HbA1c & Cholesterol \\
\hline \multirow{3}{*}{ Anti TPO } & Pearson correlation & 1 & 0.402 & -0.121 & -0.006 & -0.077 & -0.077 & -0.055 \\
\cline { 2 - 10 } & Pvalue & & $<0.001$ & 0.229 & 0.951 & 0.445 & 0.445 & 0.590 \\
\hline \multirow{2}{*}{ TSH } & Pearson correlation & 0.402 & 1 & -0.003 & -0.047 & -0.070 & -0.070 & 0.001 \\
\cline { 2 - 10 } & Pvalue & $<0.001$ & & 0.974 & 0.641 & 0.487 & 0.487 & 0.989 \\
\hline
\end{tabular}


In the study, significant positive correlation was observed between anti-TPO and TSH, i.e. with increase in anti-TPO, there was significant increase in TSH ( $\mathrm{p}$ value $<0.001^{*}$ ). Apart from this correlation, no other factors seem to be associated with TSH and Anti-TPO. There was statistically nonsignificant negative correlation between age and TSH ( $p$ value 0.974 ) and anti-TPO ( $p$ value 0.229 ). Similarly, there was statistically non-significant negative correlation between BMI and TSH ( $p$ value 0.641 ) and anti-TPO ( $p$ value 0.445 ). There was statistically non-significant negative correlation between diabetes duration and TSH ( $p$ value 0.487 ) and anti-TPO ( $p$ value 0.951 ). There was a negative correlation between $\mathrm{HbA} 1 \mathrm{c}$ and TSH and anti-TPO. Again, the correlation was not statistically significant (Table 4).

\section{Discussion}

The present study demonstrated a very high prevalence of thyroid dysfunction (42\%) in the studied sub group of subjects with diabetes. Subclinical hypothyroidism was the most frequent abnormality with a prevalence of $36 \%$, and anti-TPO positivity was seen in $30 \%$ of the subjects. Comparing to the previous studies, it is evident that this prevalence is very high, compared to the general population. The Whickham survey had found a prevalence of overt hypothyroidism of $14 / 1000$ females and $1 / 1000$ males. Subclinical hypothyroidism was recorded in $6.5 \%$ of females and $2.8 \%$ of males in this landmark survey [5]. The Colorado Thyroid Disease Prevalence study found that $9.5 \%$ of the studied population had an elevated TSH [6]. In the NHANES III study, hypothyroidism was found in $4.6 \%$ of the subjects [7].

The prevalence rate in the present study population is high even when compared to the studies held in subjects with diabetes. An Edinburgh study of 1310 subjects with diabetes showed that the overall prevalence of thyroid disease was $13.4 \%$, the highest $(31.4 \%)$ being in Type 1 diabetic females, and lowest in Type 2 diabetic males (6.9\%). The commonest category in this survey was subclinical hypothyroidism (4.8\%), followed by overt hypothyroidism $(0.9 \%)$, hyperthyroidism $0.5 \%)$, and lastly subclinical hyperthyroidism (0.5\%) [8]. In a study of 100 patients with type 2 diabetes mellitus in North India, 24\% patients were observed to have thyroid dysfunction [9]. A cross-sectional population survey in Kerala of 986 subjects showed that thyroid dysfunction was present in $19.6 \%$ of subjects [10].
Anti-TPO positivity was seen in $30 \%$ of the present study subjects. Several studies have proven the higher rates of autoimmune thyroid dysfunction in type 1 diabetes but now information is emerging regarding the higher prevalence of thyroid autoimmunity in type 2 diabetes also. Auto immunity is held responsible for the increased prevalence of thyroid dysfunction in diabetes. The 20 year followup study of Whickham Survey found that the risk of developing hypothyroidism increased with baseline serum TSH above $2 \mathrm{mU} / \mathrm{I}$ and positive anti-thyroid antibodies [11]. In a North Indian study, Anti-TPO antibodies were found in $47.36 \%$ cases of hypothyroidism.

$37.5 \%$ of the subclinical and $64.5 \%$ of the overt hypothyroid patients had anti-TPO positivity.9.2\% euthyroid subjects with type 2 diabetes were found to have positive anti-TPO antibodies [9]. The Keralian cross-sectional population survey found that among the population with normal thyroid function, $9.5 \%$ and $8.5 \%$ respectively had positive anti-TPO and anti-TG antibodies. Among those with thyroid dysfunction, $46.3 \%$ had positive anti-TPO and $26.8 \%$ were anti-TG positive [10]. Another observational study in 100 known type 2 diabetic subjects in Nigeria showed that the prevalence of anti-TPO positivity in type 2 diabetes was $10 \%$ compared to $1 \%$ in controls [12].

The present study didn't find a significant association between thyroid dysfunction and the age, duration of diabetes and BMI in this study population. But, few studies have found a positive correlation between age, BMI and thyroid dysfunction. In a retrospective study of 202 Type 2 diabetes subjects in Imphal, $16.3 \%$ of the subjects were found to have subclinical hypothyroidism and $11.4 \%$ had hypothyroidism. Prevalence of hypothyroidism was higher above 45 years, in women and BMI over 25 in that study [13].

It is important to note some of the limitations of the present study. The sample size was small compared to the other studies. Also, only one sample of TSH and FT4 was collected, which was not confirmed by a second sample at later date, as specified by the guidelines. Comparative study with controls was not done, which could have thrown more light on the difference in prevalence between different groups. Addressing these limitations might have increased the power of this study, but this study definitely sheds light on increased prevalence of thyroid dysfunction in women with type 2 diabetes. 


\section{What this study adds to the existing knowledge?}

Studies have found high prevalence of thyroid dysfunction in type 1 diabetes and hence guidelines recommend annual screening for thyroid dysfunction in type 1 diabetes only. This study highlights the fact that thyroid dysfunction is common in women with type 2 diabetes also and can be found in the absence of any symptomatology. This study demonstrates the high prevalence of thyroid autoimmunity in the studied subpopulation of women with type 2 diabetes. This study adds to the limited literature on thyroid autoimmunity and dysfunction in women with type 2 diabetes.

\section{Conclusions}

The prevalence of thyroid dysfunction is significantly high in the studied subpopulation of women with type 2 diabetes. The most common abnormality is subclinical hypothyroidism and autoimmunity is the cause of thyroid dysfunction in large proportion of these subjects. Thyroid autoimmunity is common even in euthyroid subjects. The findings of this study indicate that screening for thyroid disease among patients with diabetes should be routinely performed to be able to identify thyroid autoimmunity and diagnose subclinical hypothyroidism early.

\section{Acknowledgement}

My co-author Dr. Lalitha Ramachandrappa contributed to the collection of the study data, data compilation and analysis. She also contributed to the manuscript preparation.

\section{Reference}

01. Mirella Hage, Mira S Zantout, Sami T Azar. "Thyroid Disorders and Diabetes Mellitus". Journal of Thyroid Research. $2011 ; 7$. doi: $10.4061 / 2011 / 439463$ [Crossref]

02. Palma CC, Pavesi M, Nogueira VG, Clemente EL, Pereira MD, Pereira LC, Pacheco FF, Braga TG, de Faria Bello L, Soares JO, dos Santos SC. Prevalence of thyroid dysfunction in patients with diabetes mellitus. Diabetology \& metabolic syndrome. 2013 Dec;5(1)58.

[Crossref]
03. Kadiyala R, Peter R, Okosieme OE. Thyroid dysfunction in patients with diabetes: clinical implications and screening strategies. Int J Clin Pract. 2010 Jul;64(8)1130-9.

doi: $10.1111 /$ j.1742-1241.2010.02376.x [Crossref]

04. Duntas LH. Subclinical hypothyroidism- a misnomer in search of a new name. Thyroid. 2001 Apr;11(4)361-2.

DOI: 10.1089/10507250152039091 [Crossref]

05. Tunbridge WM, Evered DC, Hall R, et al. The spectrum of thyroid disease in a community- the Whickham survey. Clin Endocrinol (Oxf). 1977 Dec;7(6)481-93.

[Crossref]

06. Canaris GJ, Manowitz NR, Mayor G, et al. The Colorado thyroid disease prevalence study. Arch Intern Med. 2000 Feb 28;160(4)526-34.

[Crossref]

07. Hollowell JG, Staehling NW, Flanders WD, et al. Serum TSH, T(4), and thyroid antibodies in the United States population (1988 to 1994)National Health and Nutrition Examination Survey (NHANES III). J Clin Endocrinol Metab. 2002 Feb;87(2)489-99.

DOI: $10.1210 /$ jcem.87.2.8182 [Crossref]

08. Perros P, McCrimmon RJ, Shaw G, et al. Frequency of thyroid dysfunction in diabetic patients- value of annual screening. Diabet Med. 1995 Jul;12(7)622-7.

[Crossref]

09. Kaeley N, Bhatia R, Dhar M, Verma SK, Ahmed S. Association of Thyroid Disorders and Type 2 Diabetes Mellitus-Beyond Coincidence a Hos pital Based Study From Sub-Himalayan Region. National J Med Allied Sci. 2015;4(1)19-25. [Crossref]

10. Usha Menon V, Sundaram KR, Unnikrishnan AG, et al. High prevalence of undetected thyroid disorders in an iodine sufficient adult south Indian population. J Indian Med Assoc. 2009 Feb;107(2)72-7.

[Crossref]

11. Vanderpump MP, Tunbridge WM, French JM, et al. The incidence of thyroid disorders in the community- a twenty-year follow-up of the Whickham Survey. Clin Endocrinol (Oxf). 1995 Jul;43(1)55-68.

¡Crossref] 
12. Nwokolo I, Meludu C, Dioka E, Onah CE, Ikemefuna FO, Onyema-Ilo OB. The Prevalence of Thyroid Dysfunction and Thyroid Autoantibodies among Type 2 diabetic Patients in Nnewi, South Eastern Nigeria. JMSCR. $2014 ; 2 ; 646-53$.

[Crossref]
13. Demitrost $L$, Ranabir S. Thyroid dysfunction in type 2 diabetes mellitus- A retrospective study. Indian J Endocrinol Metab. 2012 Dec;16(Suppl 2)S334-5.

doi: $10.4103 / 2230-8210.104080$ [Crossref] 